\title{
Targeted covalent inhibitors of MDM2 using electrophile-bearing stapled peptidest
}

Received 00th January 20xx, Accepted 00th January 20xx DOI: $10.1039 / \times 0 \times x 00000 x$

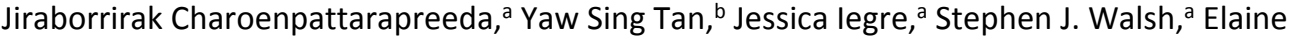 \\ Fowler, ${ }^{a}$ Rohan Eapen, ${ }^{c}$ Yuteng Wu, ${ }^{a}$ Hannah F. Sore, ${ }^{a}$ Chandra S. Verma, bde Laura Itzhakic and \\ David R. Spring*a
}

Herein, we describe the development of a novel staple with an electrophilic warhead to enable the generation of stapled peptide covalent inhibitors of the $\mathrm{P53}-\mathrm{MDM} 2$ protein-protein interaction (PPI). The peptide developed showed complete and selective covalent binding resulting in potent inhibition of p53-MDM2 PPI.

Targeted covalent inhibitors (TCls) are a class of molecules that have been increasing in popularity and are reviving the field of covalent inhibitors. ${ }^{1}$ TCls employ weak electrophile warheads in their structure that, upon ligand binding, can react with a nucleophilic residue of the target protein. This results in a more controlled and selective binding towards the site of interest. The covalent bond only forms when the "warhead" is brought into close proximity of the appropriately located nucleophilic residue as a consequence of the inhibitor binding to the designed pocket. ${ }^{\text {1a }}$ Compared to non-covalent inhibitors, TCls can offer several advantages which include the potential for improved potency, ${ }^{2}$ longer duration of action, ${ }^{3}$ improved selectivity, and the possibility for inhibiting 'intractable' targets. ${ }^{1 \mathrm{a}, 4,5}$

Most covalent inhibitors have been designed to target a cysteine residue near the substrate binding site due to its low abundance in the proteome and its unique reactivity. ${ }^{6}$ However, not all binding sites contain cysteine residues in the ideal proximity. ${ }^{7}$ Lysine is more ubiquitous than Cys and has been targeted in a wide variety of biological systems; ${ }^{1 b, 7}$ however, examples of inhibitors targeting surface-exposed lysine are rare. The challenge for targeting the $\varepsilon-\mathrm{NH}_{2}$ group of Lys is its high $\mathrm{pK}_{\mathrm{aH}}(10.4)$ which renders $99.9 \%$ of the amino

\footnotetext{
a. Department of Chemistry, University of Cambridge, Lensfield Road, CB2 1EW, Cambridge, UK. E-mail: spring@ch.cam.ac.uk

b. Bioinformatics Institute, Agency for Science, Technology and Research (A*STAR), 30 Biopolis Street, \#07-01 Matrix, Singapore 138671

c. Department of Pharmacology, University of Cambridge, Tennis Court Road, Cambridge CB2 1PD, UK

d. Department of Biological Sciences, National University of Singapore, 14 Science

Drive 4, Singapore 117543

e. School of Biological Sciences, Nanyang Technological University, 60 Nanyang Drive, Singapore 637551

tElectronic Supplementary Information (ESI) available: Supplementary figures, experimental procedures and compound characterisation data. See DOI: $10.1039 / x 0 x x 00000 x$
}

group protonated under physiological conditions. ${ }^{8}$ Nonetheless, surface-exposed lysine can be targeted following a careful design. ${ }^{\text {th }}$

MDM2, an E3 ubiquitin ligase, is a negative regulator of the tumour suppressor $\mathrm{p} 53^{9}$ and ubiquitination of $\mathrm{p} 53$ limits its activity. ${ }^{10}$ Approximately $50 \%$ of human cancers possess mutated $\mathrm{p} 53$, whilst others overexpressed MDM2 resulting in the malignant cells being able to escape apoptosis. ${ }^{11}$ Therefore, inhibition of the p53-MDM2 PPI presents a potential target for cancer therapy as documented by at least 10 compounds currently in clinical trials. ${ }^{12}$

Because PPIs generally have relatively large and shallow binding pockets, ${ }^{13}$ peptides are a suitable choice for inhibiting them due to their greater contact surface area, similar to native proteins, compared to small molecules. However, peptides on their own may suffer from poor proteolytic stability and bioavailability. ${ }^{14}$ One of the most successful approaches to inhibit PPIs and overcome the intrinsic limitations of peptides is the use of stapled peptides - e.g. peptides constrained into their binding conformation by chemically cross-linking two amino acid side chains. ${ }^{14 a, c, d}$ In the case of the p53-MDM2 PPI, several stapled peptides have been developed with one example, ALRN-6924, reaching phase II clinical trials. ${ }^{14 b, d, 15}$

A recent example of a $\mathrm{TCl}$ is the stapled peptide $\mathrm{mSF}-\mathrm{SAH}$, which was developed to target the p53-MDM2/4 proteinprotein interaction (PPI) covalently. ${ }^{16}$ Hoppmann and Wang incorporated an unnatural amino acid with an electrophilic sulfonyl fluoride group into the peptide sequence targeting a lysine or histidine residue near the binding site on MDM2/4; one-component peptide stapling was then used to constrain the peptide (Scheme 1a). ${ }^{16}$

Inspired by the work of Hoppmann and Wang, ${ }^{16}$ we proposed to utilise the non-covalent binding of a stapled peptide to bring the electrophile into proximity of the targeted surface-exposed Lys residue near the MDM2 binding site. Thus, the covalent ligand-protein cross-linking is facilitated via proximity-enabled bioreactivity (Scheme 1b). ${ }^{17}$ The resulting covalent linkage would prevent peptide dissociation and provide better inhibitory activity. Unlike previous reports, we 


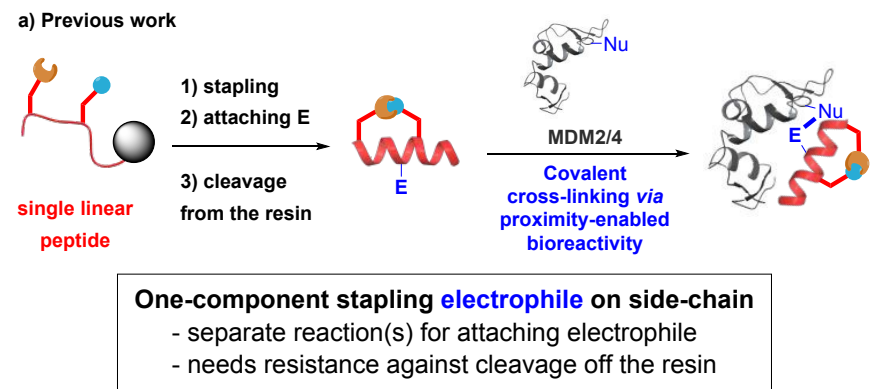

b) This work

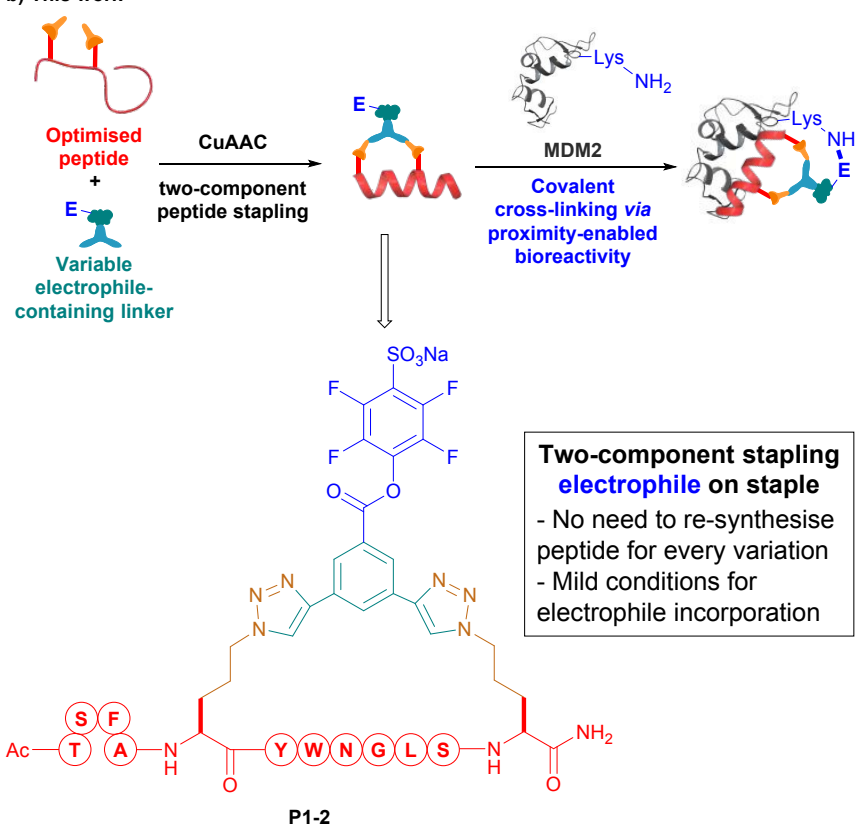

Scheme 1 a) Previous work using one-component stapling and incorporation of an electrophilic moiety into the peptide sequence for generating a stapled peptide covalent inhibitor for MDM2/4. ${ }^{16}$ Covalent-crosslinking occurs through proximityenabled bioreactivity. ${ }^{17}$ Shaded circle denotes resin. $\mathrm{Nu}=$ Lys or His b) Utilising 2C-PS for generation of stapled peptide covalent inhibitors. Structure of P1-2, the developed stapled peptide covalent inhibitor, is shown.

envisioned to introduce the electrophilic warhead on a staple core compatible with the copper-catalysed azide-alkyne cycloaddition two-component peptide stapling (CuAAC 2CPS). ${ }^{14 d}$ The use of 2C-PS improves the efficiency of the optimisation process as each variation of the staple does not require a completely new synthesis of each peptide. ${ }^{18}$ Moreover, CUAAC 2C-PS provides mild conditions with reactions conducted at room temperature in aqueous solution and are compatible with unprotected peptides. We envisaged that by placing the electrophile on the staple and utilising a $2 \mathrm{C}$ PS approach, simpler proximity tuning, staple screening, and synthesis can be achieved (Scheme 1b).

Initial analysis of the binding site of MDM2 (PDB code: $5 A F G)^{15 d}$ suggested that the solvent-exposed Lys94 may be a feasible residue for covalent targeting (Fig. 1a). Molecular modelling methods were used to determine the optimal peptide sequence, staple position, and staple structure for covalent binding with Lys $94 .{ }^{19}$ We decided to adopt the phagederived peptide PMI sequence (H-TSFAEYWNLLSP-OH) as the basis for our stapled peptide because it offers strong MDM2 a)

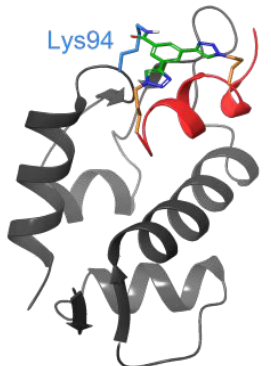

b)

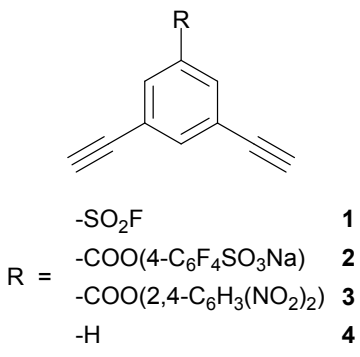

c) P1: $\mathrm{Ac}-\mathrm{T}(\mathrm{S})(\mathbf{A})\left(\mathbf{X}, \mathbf{Y}(\mathbf{N})(\mathrm{G})\left(\mathbf{S}-\mathrm{NH}_{2}\right.\right.$ where $\mathrm{X}=\mathrm{Orn}\left(\mathrm{N}_{3}\right)$

Fig. 1 a) Molecular dynamics simulation of PMI-derived stapled peptide (red) covalently linked with MDM2 (grey) through amide bond with Lys94 close to the binding site. b) The structures of the proposed staples: aryl sulfonyl fluoride $\mathbf{1}$ sulfotetrafluorophenyl (STP) ester 2, and dinitrophenyl ester $\mathbf{3}$. The non-electrophilic staple $\mathbf{4}$ was used as a control. c) The optimal linear diazidopeptide P1.

binding ability and good aqueous solubility. ${ }^{20}$ We employed the same azido-ornithine amino acid and 1,3-diethynylbenzene staple (4, Fig. 1b) that were used by Lau et al. for $i, i+72 \mathrm{C}-\mathrm{PS}$ in our molecular models, ${ }^{14 \mathrm{~b}}$ which showed that the optimal staple positions are at residues 5 and 12 , such that an electrophilic group at the 5-position of the staple could come into close contact with Lys94. Leu9 was mutated to Gly to prevent steric clash of the side chain with the staple (Fig. S1, $\mathrm{ESI}+$ ). As a result, the peptide $\mathbf{P 1}$ was identified as the optimal sequence to position the electrophilic staple in the correct location for targeting Lys94 (Fig. 1C).

We chose a sulfonyl fluoride and two activated esters for initial screening of possible electrophiles (Fig. 1b). The sulfonyl fluoride electrophile (1) was selected based upon previous reports of its resistance to reduction, hydrolysis, and exclusivity to heterolytic cleavage. ${ }^{21}$ In addition, its biological application has been demonstrated through a plethora of examples including peptidic and Lys-targeted small-molecule binders. ${ }^{16,22}$ Whereas, activated esters, namely sulfotetrafluorophenyl (STP) ester (2) and 2,4-dinitrophenyl ester (3), were chosen due to their harder electrophilic character which makes them more susceptible to an attack by an amine relative to a thiol. Moreover, activated esters are validated probes for proteomic profiling for lysine reactivity. ${ }^{23}$ Molecular dynamics simulations showed that the ester and sulfonamide covalent complexes of the two-component stapled P1 with Lys94 of MDM2 are stable, with the three key binding residues of the peptide (Phe3, Trp7, and Leu10) remaining bound within the p53-binding cleft at the end of all simulations (Fig. S1, ESI + ).

Considering these data, we designed compounds 1-3 as potential electrophile-containing staples (Fig. 1b). Staples 1, 2, and $\mathbf{3}$ were then synthesised and tested for their compatibility with the CuAAC 2C-PS, ${ }^{18}$ stability in aqueous media, and reactivity towards lysine. Compound $\mathbf{3}$ was insoluble in aqueous conditions; thus, it was excluded from further testing. Despite the comparable stability of staples $\mathbf{1}$ and $\mathbf{2}$ in physiological pH (49\% intact for 1 vs $42 \%$ for 2 after 24 h, Fig. 2a), activated ester $\mathbf{2}$ was progressed as it was found to be significantly more stable under the CuAAC 2C-PS conditions (15\% intact for 1 vs $83 \%$ for $\mathbf{2}$ after 24 h, Fig. 2b). In addition, 2 showed a faster reactivity with Lys whilst 1 mostly underwent 

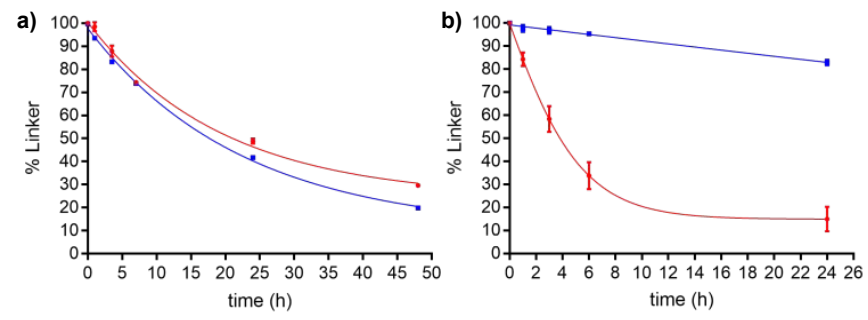

c)

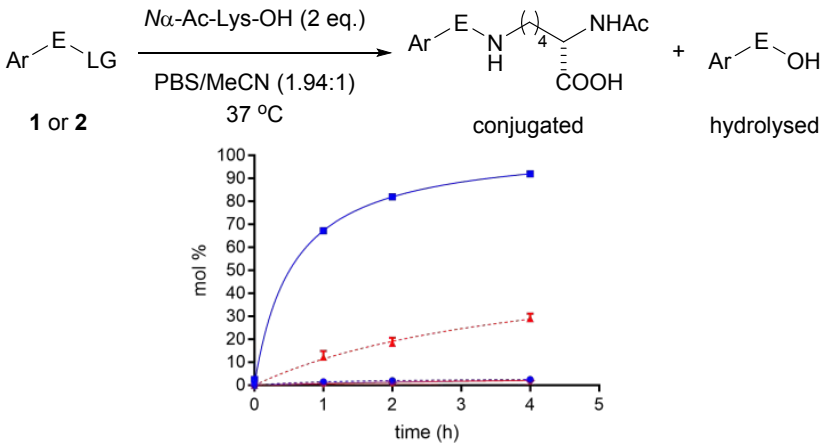

Fig. 2 Stability and reactivity tests of compounds $\mathbf{1}$ (red) and $\mathbf{2}$ (blue) a) Stability in aqueous media: PBS (1x): $\operatorname{MeCN}(1.94: 1), 37^{\circ} \mathrm{C}$. b) Stability in CuAAC condition $t \mathrm{BuOH} /$ water (1:1), 1.1 eq. of the compound $\left(0.73 \mathrm{mM}\right.$ ), $\mathrm{CuSO}_{4} .5 \mathrm{H}_{2} \mathrm{O}$ (1 eq.), THPTA (1 eq.) and Na-L-ascorbate ( 3 eq.) at rt. c) Reactivity comparison between compounds 1 and 2 against $\mathrm{N} \alpha$-Ac-Lys-OH. Conditions: PBS (1x): MeCN (1.94:1), 1 mM concentration of the compound, $N \alpha-A c-L y s-O H(2$ eq.). $E=$ electrophile, $L G=$ leaving group. Solid lines indicate conjugation while dotted lines indicate hydrolysis. All reactions were monitored by analytical HPLC and caffeine was used as the internal standard. The results are average of two independent repeats and the errors shown as standard errors of mean.

hydrolysis (5\% Lys-conjugated for 1 vs $95 \%$ for $\mathbf{2}$ after 4 h, Fig. 2c). With these results in hand, we decided to take forward the STP ester $\mathbf{2}$ as our electrophile-containing staple. The optimised peptide $\mathbf{P} \mathbf{1}$ was stapled with compound $\mathbf{2}$ to obtain the stapled peptide P1-2 (Scheme S1, ESI + ). Pleasingly, circular dichroism measurements confirmed the staple used was able to enhance the $\alpha$-helical conformation of the peptide (12\% for P1 vs 22\% for P1-2, Fig. S2, ESIt).

In order to assess the ability of P1-2 to form a covalent complex with MDM2, P1-2 was incubated with MDM2 and the reaction mixture analysed by mass spectrometry (Fig. 3). After the incubation, complete formation of the covalent complex was observed and no unmodified MDM2 remained (Fig. 3a-b) Pleasingly, by replacing P1-2 with the control peptide P1-4 (no electrophilic moiety, Scheme S1, ESIt), detection of a covalent peptide-MDM2 complex was not observed (Fig. S3, ESI†).

Under the same conditions, mass spectrometry results of the STP ester 2 alone (i.e. without peptide) with MDM2 resulted in only a small amount of the protein being modified, therefore highlighting the importance of the specific noncovalent binding of P1-2 to MDM2 for the cross-linking event to occur (Fig. 3c).

The selectivity of the stapled peptide was investigated further by the addition of human lysozyme (Lyz) to the incubation. Lyz contains five highly solvent-accessible lysine residues out of which, one is particularly active. ${ }^{24}$ Following the incubation, formation of the peptide-lysozyme covalent complex was not detected indicating that P1-2 selectively binds MDM2 (Fig. S4).

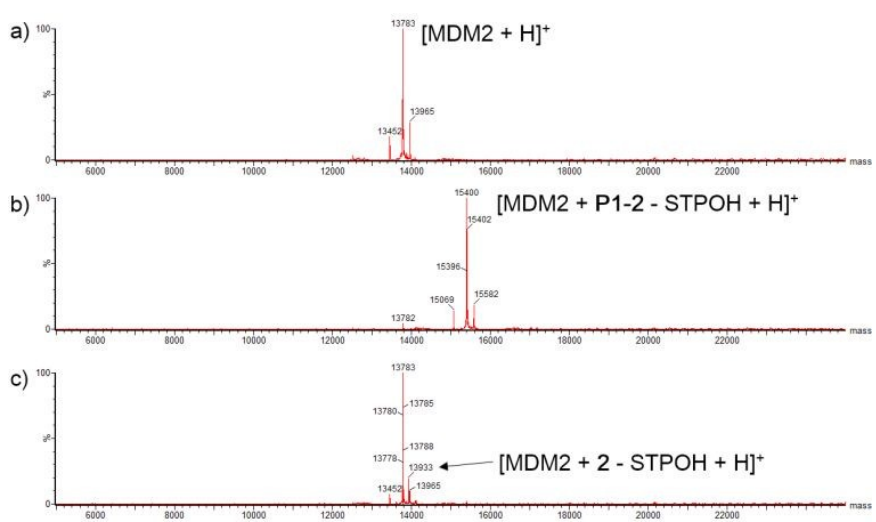

Fig. 3 ESI-MS spectra for reactions with MDM2 a) the unmodified MDM2. [MDM2 $+\mathrm{H}]^{+}$ = 13783 Da. b) P1-2 (25 $\mu \mathrm{M})$ was incubated with MDM2 $(25 \mu \mathrm{M})$ in PBS buffer $(+10 \%$ DMSO) at $37{ }^{\circ} \mathrm{C}$ for $1 \mathrm{~h}$. ESI-MS spectrum of the reaction indicated the complete covalent binding of the stapled peptide. [MDM2 + P1-2 $-\mathrm{STPOH}+\mathrm{H}]^{+}=15400 \mathrm{Da} \mathrm{c}$ ) The same incubation as in b) but with P1-2 replaced with compound 2. ESI-MS spectrum showed low reactivity of the electrophile on its own with most MDM2 unreacted. $[\mathrm{MDM} 2+\mathbf{2}-\mathrm{STPOH}+\mathrm{H}]^{+}=13933 \mathrm{Da} ; \mathrm{STPOH}=$ sulfotetrafluorophenol a)

\begin{tabular}{cc}
\hline Peptide & $K_{d}(n M){ }^{\dagger}$ \\
\hline WT PMI & $16.6 \pm 0.2$ \\
P1 & $47.8 \pm 1.5$ \\
P1-4 & $19.3 \pm 0.3$ \\
\hline
\end{tabular}

c)

\begin{tabular}{cc}
\hline $\begin{array}{c}\text { Time } \\
(\min )\end{array}$ & $\begin{array}{c}\mathrm{K}_{\mathrm{d}, \mathrm{app}} \text { of } \\
\mathbf{P 1 - 2}(\mathrm{nM})\end{array}$ \\
\hline 9 & $30.0 \pm 9.2$ \\
41 & $12.9 \pm 4.1$ \\
120 & $7.1 \pm 2.1$ \\
\hline
\end{tabular}

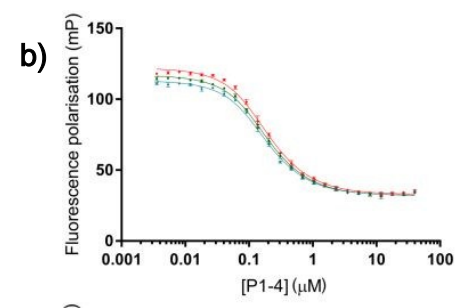

d)

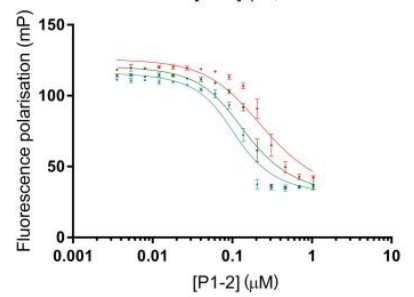

Fig. 4 a) Dissociation constants for non-covalent peptides. TThe $K_{d}$ values are the average of every time point and the errors are standard errors of mean. b) Competitive FP assay of P1-4 showing no change in affinity over time. Each curve represents one time point: $9 \mathrm{~min}$ (red), $41 \mathrm{~min}$ (green), and $120 \mathrm{~min}$ (blue). Each data point is arithmetic mean of triplicate and the errors shown are standard errors of mean. $c$ ) Apparent dissociation constant of P1-2 at each time point. d) Competitive FP assay of P1-2 showing the increase of the apparent dissociation constant over time which is characteristic of a covalent inhibitor.

Finally, the apparent dissociation constant $\left(\mathrm{K}_{\mathrm{d}, \mathrm{app}}\right)$ of P1-2 to MDM2 was examined and compared to the non-covalent peptides using a competitive fluorescence polarisation (FP) assay (Fig. 4). ${ }^{14 b, 15 c}$ The linear diazidopeptide $\mathbf{P 1}$ was found to have an attenuated dissociation constant for MDM2 $\left(K_{d}=47.8\right.$ $\pm 1.5 \mathrm{nM}$, Fig. 4a) compared to the wild-type (WT) PMI $\left(\mathrm{K}_{\mathrm{d}}=\right.$ $16.6 \pm 0.2 \mathrm{nM}$, Fig. 4a). ${ }^{20}$ Pleasingly, the stapled peptide P1-4 showed an affinity comparable to the WT $\left(K_{d}=19.3 \pm 0.3 \mathrm{nM}\right.$, Fig. 4a). Crucially, over the course of 120 minutes, these dissociation constants did not change significantly (Fig. 4b, S56, ESI+). In contrast, as expected for a $\mathrm{TCl}$, the apparent dissociation constant of P1-2 improved over time as the covalent bond was formed, ultimately resulting in a potent MDM2 inhibitor after 120 minutes $\left(K_{d, \text { app }}=30.0 \pm 9.2 \mathrm{nM}\right.$ at 9 min which decreased to $7.1 \pm 2.1 \mathrm{nM}$ at $120 \mathrm{~min}$, Fig. $4 \mathrm{c}-\mathrm{d}$ ). ${ }^{25}$, $\neq$

In summary, we have developed a novel strategy for producing stapled peptide covalent inhibitors. Expanding on 
our CUAAC 2C-PS technique, the staple was functionalised with a suitable electrophile for forming a covalent cross-linking with the target protein upon binding. We validated this approach using an STP ester-functionalised stapled peptide targeting the oncogenic protein MDM2: the lead peptide P1-2 demonstrated complete covalent complex formation and $\mathrm{nM}$ inhibition to MDM2.

Importantly, the results and concept of our study would expedite the development of stapled peptide covalent inhibitors by removing the need to synthesise the peptides anew for every sequence and requiring less demanding conditions on the electrophile. We envision that targeting proteins with low turnover rates would gain the most benefit from using this strategy. ${ }^{1 a, 7 a} A$ further advantage of using the CUAAC 2C-PS technique is that extra functionalisation may be achieved by appending a second functional handle to the staple and hence further enhance the capability of peptide inhibitors.

The research was supported by grants from the Engineering and Physical Sciences Research Council, Biotechnology and Biological Sciences Research Council, Medical Research Council and Royal Society. JC and JI would like to thank Trinity College, Cambridge for funding. YST and CSV would like to thank A*STAR (IAF-PP H17/01/a0/010) for support.

\section{Conflicts of interest}

There are no conflicts to declare.

\section{Notes and references}

₹ Due to the instability of MDM2 in the assay, data for time-points beyond 120 minutes were not obtained.

1 (a) T. A. Baillie, Angew. Chem. Int. Ed., 2016, 55, 13408-13421; (b) M. Gehringer and S. A. Laufer, J. Med. Chem., 2019, DOI 10.1021/acs.jmedchem.8b01153; (c) E. Anscombe, E. Meschini, R. Mora-Vidal, S. R. Wedge, J. A. Endicott, R. J. Griffin, M. P. Martin, D. Staunton, M. Geitmann, U. H. Danielson, W. A. Stanley, L. Z. Wang, T. Reuillon, B. T. Golding, C. Cano, D. R. Newell and M. E. M. Noble, Chem. Biol., 2015, 22, 1159-1164 (d) S. E. Dalton, L. Dittus, D. A. Thomas, M. A. Convery, J. Nunes, J. T. Bush, J. P. Evans, T. Werner, M. Bantscheff, J. A. Murphy and S. Campos, J. Am. Chem Soc., 2018, 140, 932-939; (e) T. Tamura, T. Ueda, T. Goto, T. Tsukidate, Y. Shapira, Y. Nishikawa, A. Fujisawa and I. Hamachi, Nat. Commun., 2018, 9 1870; (f) M. J. Evans, A. Saghatelian, E. J. Sorensen and B. F. Cravatt, Nat Biotechnol., 2005, 23, 1303-1307; (g) M. J. Evans, G. M. Morris, J. Wu, A. J. Olson, E. J. Sorensen and B. F. Cravatt, Mol. Biosyst., 2007, 3, 495; (h) G. Akçay, M. A. Belmonte, B. Aquila, C. Chuaqui, A. W. Hird, M. L. Lamb, P. B. Rawlins, N. Su, S. Tentarelli, N. P. Grimster and Q. Su, Nat. Chem. Biol., 2016, 12, 931-936.

2 A. J. T. Smith, X. Zhang, A. G. Leach and K. N. Houk, J. Med. Chem., 2009, 52, 225-233.

3 G. Sachs, J. M. Shin and C. W. Howden, Aliment. Pharmacol. Ther., 2006, 23, 28.

4 T. Barf and A. Kaptein, J. Med. Chem., 2012, 55, 6243-6262.

5 R. Lonsdale and R. A. Ward, Chem. Soc. Rev., 2018, 47, 3816-3830.

6 (a) S. M. Marino and V. N. Gladyshev, J. Mol. Biol., 2010, 404, 902-916; (b) D. A. Shannon and E. Weerapana, Curr. Opin. Chem. Biol., 2015, 24, 18-26; (c) S. $\mathrm{Wu}, \mathrm{H}$. Luo, H. Wang, W. Zhao, Q. Hu and Y. Yang, Biochem. Biophys. Res. Commun., 2016, 478, 1268-1273; (d) R. Lagoutte, R. Patouret and N. Winssinger, Curr. Opin. Chem. Biol., 2017, 39, 54-63.
7 (a) J. Pettinger, K. Jones and M. D. Cheeseman, Angew. Chem. Int. Ed, 2017 56, 15200-15209; (b) A. Cuesta and J. Taunton, Andol: Revi Bijochegr, 2019, 88 DOI: 10.1146/annurev-biochem-061516-044805

8 G. Platzer, M. Okon and L. P. McIntosh, J. Biomol. NMR, 2014, 60, 109-129.

9 A. Burgess, K. M. Chia, S. Haupt, D. Thomas, Y. Haupt and E. Lim, Front. Oncol., 2016, 6, 1-7.

10 (a) Y. Haupt, R. Maya, A. Kazaz and M. Oren, Nature, 1997, 387, 296-299; (b) R. Honda, H. Tanaka and H. Yasuda, FEBS Lett., 1997, 420, 25-27.

11 (a) S. Shangary and S. Wang, Clin. Cancer Res., 2008, 14, 5318-5324; (b) F. S. Leach, T. Tokino, P. Meltzer, M. Burrell, J. D. Oliner, S. Smith, D. E. Hill, D. Sidransky, K. W. Kinzler and B. Vogelstein, Cancer Res., 1993, 53, 2231-4; (c) J. D. Oliner, K. W. Kinzler, P. S. Meltzer, D. L. George and B. Vogelstein, Nature, 1992, 358, 80-83.

12 (a) V. Tisato, R. Voltan, A. Gonelli, P. Secchiero and G. Zauli, J. Hematol. Oncol., 2017, 10, 133; (b) D. Nguyen, W. Liao, S. X. Zeng and H. Lu, Pharmacol. Ther., 2017, 178, 92-108; (c) A. Aguilar, J. Lu, L. Liu, D. Du, D. Bernard, D. McEachern, S. Przybranowski, X. Li, R. Luo, B. Wen, D. Sun, H. Wang, J. Wen, G. Wang, Y. Zhai, M. Guo, D. Yang and S. Wang, J. Med. Chem., 2017, 60, 2819-2839.

13 (a) D. E. Scott, A. R. Bayly, C. Abell and J. Skidmore, Nat. Rev. Drug Discov., 2016, 15, 533-550; (b) J. A. Wells and C. L. McClendon, Nature, 2007, 450, 1001-1009.

14 (a) L. D. Walensky and G. H. Bird, J. Med. Chem., 2014, 57, 6275-6288; (b) Y. H. Lau, P. de Andrade, S.-T. Quah, M. Rossmann, L. Laraia, N. Sköld, T. J. Sum, P. J. E. Rowling, T. L. Joseph, C. Verma, M. Hyvönen, L. S. Itzhaki, A. R. Venkitaraman, C. J. Brown, D. P. Lane and D. R. Spring, Chem. Sci., 2014, 5, 1804-1809; (c) Y. H. Lau, P. de Andrade, Y. Wu and D. R. Spring, Chem. Soc. Rev., 2015, 44, 91-102; (d) J. legre, J. S. Gaynord, N. S. Robertson, H. F. Sore, M. Hyvönen and D. R. Spring, Adv. Ther., 2018, 1, 1800052

15 (a) F. Bernal, A. F. Tyler, S. J. Korsmeyer, L. D. Walensky and G. L. Verdine, J. Am. Chem. Soc., 2007, 129, 2456-2457; (b) Y. S. Chang, B. Graves, V. Guerlavais, C. Tovar, K. Packman, K.-H. To, K. A. Olson, K. Kesavan, P. Gangurde, A. Mukherjee, T. Baker, K. Darlak, C. Elkin, Z. Filipovic, F. Z. Qureshi, H. Cai, P. Berry, E. Feyfant, X. E. Shi, J. Horstick, D. A. Annis, A. M. Manning, N. Fotouhi, H. Nash, L. T. Vassilev and T. K. Sawyer, Proc. Natl. Acad. Sci. U. S. A., 2013, 110, E3445-E3454; (c) C. J. Brown, S. T. Quah, J. Jong, A. M. Goh, P. C. Chiam, K. H. Khoo, M. L. Choong, M. A. Lee, L. Yurlova, K. Zolghadr, T. L. Joseph, C. S. Verma and D. P. Lane, ACS Chem. Biol., 2013, 8, 506-512; (d) Y. H. Lau, Y. Wu, M. Rossmann, B. X. Tan, P. de Andrade, Y. S. Tan, C. Verma, G. J. McKenzie, A. R. Venkitaraman, M. Hyvönen and D. R. Spring, Angew. Chem. Int. Ed., 2015, 54, 15410-15413; (e) K. Hu, F. Yin, M. Yu, C. Sun, J. Li, Y. Liang, W. Li, M. Xie, Y. Lao, W. Liang and Z.-G. Li, Theranostics, 2017, 7, 4566-4576; (f) X. Li, W. D. Tolbert, H.-G. Hu, N. Gohain, Y. Zou, F. Niu, W.-X. He, W. Yuan, J.-C. Su, M. Pazgier and W. Lu, Chem. Sci., 2019, 10, 1522-1530.

16 C. Hoppmann and L. Wang, Chem. Commun., 2016, 52, 5140-5143.

17 Z. Xiang, H. Ren, Y. S. Hu, I. Coin, J. Wei, H. Cang and L. Wang, Nat. Methods, 2013, 10, 885-888.

18 Y. H. Lau, Y. Wu, P. De Andrade, W. R. J. D. Galloway and D. R. Spring, Nat. Protoc., 2015, 10, 585-594.

19 Y. S. Tan, D. P. Lane and C. S. Verma, Drug Discov. Today, 2016, 21, 1642 1653.

20 M. Pazgier, M. Liu, G. Zou, W. Yuan, C. Li, C. Li, J. Li, J. Monbo, D. Zella, S. G. Tarasov and W. Lu, Proc. Natl. Acad. Sci. U. S. A., 2009, 106, 4665-4670.

21 J. Dong, L. Krasnova, M. G. Finn and K. Barry Sharpless, Angew. Chem. Int. Ed., 2014, 53, 9430-9448.

22 (a) N. N. Gushwa, S. Kang, J. Chen and J. Taunton, J. Am. Chem. Soc., 2012, 134, 20214-20217; (b) A. J. Brouwer, A. Jonker, P. Werkhoven, E. Kuo, N. Li, N. Gallastegui, J. Kemmink, B. I. Florea, M. Groll, H. S. Overkleeft and R. M. J. Liskamp, J. Med. Chem., 2012, 55, 10995-11003; (c) N. P. Grimster, S. Connelly, A. Baranczak, J. Dong, L. B. Krasnova, K. B. Sharpless, E. T. Powers, I. A. Wilson and J. W. Kelly, J. Am. Chem. Soc., 2013, 135, 5656-5668; (d) Q. Zhao, X. Ouyang, X. Wan, K. S. Gajiwala, J. C. Kath, L. H. Jones, A. L. Burlingame and J. Taunton, J. Am. Chem. Soc., 2017, 139, 680-685.

23 S. M. Hacker, K. M. Backus, M. R. Lazear, S. Forli, B. E. Correia and B. F. Cravatt, Nat. Chem., 2017, 9, 1181-1190.

24 M. Ahn, E. De Genst, G. S. Kaminski Schierle, M. Erdelyi, C. F. Kaminski, C. M. Dobson and J. R. Kumita, PLoS One, 2012, 7, e50192.

25 J. Singh, R. C. Petter, T. A. Baillie and A. Whitty, Nat. Rev. Drug Discov., 2011, 10, 307-317. 